\title{
Acoustic location of conspecifics in a nocturnal bird: the corncrake Crex crex
}

\author{
Paweł Ręk
}

Received: 27 March 2013 / Revised: 27 June 2013 / Accepted: 2 July 2013 / Published online: 20 July 2013

(C) The Author(s) 2013. This article is published with open access at Springerlink.com

\begin{abstract}
Although the use of sounds in spatial orientation is widespread among animals, only a few groups advanced such specific adaptations as echolocation. In contrast, practically all animals and night-active species in particular, must occasionally orient themselves relative to invisible but audible objects such as a hidden rival or predator. In this study, I would like to determine the impact of locating which involves the use of acoustic parameters of sender's vocalisations by receivers and changes of positions and triangulation of sender's vocalisations by receivers in estimating the distance to the sender during night-time territorial interactions of the corncrake (Crex crex). Males were subjected to two kinds of stimuli: approaching one, imitating the change of the distance of the calling intruder toward the focal male while keeping the direction constant, or stationary stimuli, involving acoustic stimulation with no motion. Although males subjected to approaching stimulation moved longer distances, in both stimuli groups, males moved predominantly toward or out of the playback speaker, and only occasionally made sideway movements. However, the results gave no evidence of corncrakes moving specifically in order to locate the source of the sound; they suggest that males moved toward or away from the already located sound. The fact that males moved longer distances in response to approaching than stationary stimuli indicates that they were able to perceive the change of the distance to the playback speaker based only on structural parameters or amplitude of the calls played.
\end{abstract}

Keywords Sound location - Triangulation · Distance assessment $\cdot$ Corncrake $\cdot$ Crex crex

\footnotetext{
P. Ręk $(\bowtie)$

Department of Behavioural Ecology, Adam Mickiewicz University, Umultowska 89, 61-614 Poznan, Poland

e-mail: rek@amu.edu.pl
}

\section{Introduction}

Spatial orientation is based on integration of information collected from the surrounding environment with the use of senses. In birds, vision is of primary importance; however, other senses can also play important role (Ioalè et al. 1990; Walcott 1996; Witten et al. 2010), and the actual hierarchy of cues appears to depend strongly on the spatial scale. Generally, birds are not well adapted to conditions of zero visibility and except for some cave-dwelling oilbirds and swiftlets, which have evolved some rudimentary echolocation (Jordan Price et al. 2004), and owls, which position acoustic signals with great accuracy (Knudsen et al. 1979; Konishi 2003), the ability of birds to use sounds to locate objects does not rival that of the bats or dolphins. Nevertheless, birds must sometimes orient relative to invisible acoustic objects such as a hidden rival or predator.

There are many mechanisms enabling the listener to estimate both the direction and distance to the source of the sound. The direction is relatively easy to asses by the listener having two ears because the sound intensity difference and arrival time or sound wave phase difference that occur at two ears act as cues that enable the listener to perceive the direction of the source of the sound (Makita 1962). Many bird species mastered passive acoustic location to perfection, with owls being the most specialised birds for hearing (Coles and Guppy 1988). By contrast, the estimation of the distance to the source of the sound is more complicated, mostly because it is strongly affected by local conditions and the acoustic structure of sounds transmitted through the environment (Brumm and Naguib 2009). The most obvious distance cue appears to be the sound amplitude; however, except for the distance, amplitude depends strongly on the degree of sender's arousal (Brumm and Ritschard 2011), the so-called Lombard effect (Brumm and Zollinger 2011) and the directionality of the sound (i.e. direction towards which the singer is facing). Hence, it is questionable that birds actually use 
amplitude as the principal ranging cue. But birds can use other cues that change predictably with transmission distance, particularly the accumulation of reverberations and frequency-dependent attenuation (Waas 1991; Naguib 1995; Naguib et al. 2000; Naguib and Wiley 2001; Marler 2004; Slabbekoorn 2004). Finally, it is possible for birds to measure the distance to the auditory stimuli actively by triangulation, that is by measuring the direction to the stimuli from at least two different locations and when the distance is too long for triangulation only based on the simultaneous use of two ears. Nevertheless, this possibility has not been tested so far. The main objective of this study is to determine the impact of passive (with the use acoustic parameters of vocalisations) and active (involving movements and triangulation) sound location in estimating the distance to the sender in lightlimited conditions. This objective was achieved with the experiment based on social interactions of the corncrake (Crex crex) males.

The corncrake is a typical cryptic rale species, active mostly during the night. Males communicate intensively using repetitious cracking calls, characterised by high amplitude and long range. They interact vocally with each other in communication networks consisting of several individuals (1-20). Such system appears to be an example of an exploded lek (Alonso et al. 2012), in which information exchange among males is almost restricted to the auditory channel. At the same time, such interactions are almost two dimensional because males inhabit low vegetation and fly with reluctance. Therefore, the corncrake is a very suitable subject for studying the location of a sound source based solely on acoustic cues.

The concept of the experiment was based on testing the impact of the distance and direction cues on the movements of birds separately with the use of either approaching or stationary stimuli. The function of the approaching stimulation was to imitate the change of the distance of the intruder male to the focal male (movement toward the male) while keeping the direction to the intruder constant (no sideway movements), whereas trials with stationary stimuli functioned as control group in which both the distance and angle were constant. Generally, intrusion by itself initiates aggressive responses or retreats by territory owners but the nature of the response depends on the risk assessment. Distance to the intruder is a crucial risk assessment factor (Waas 1991). Consequently, I assumed that the first reaction of the focal male is the assessment of the distance to the playback speaker (risk assessment). This could be achieved either by the assessment of structural parameters of calls, which could change only with distance (calling samples were homogenous with this respect), or by active movements by the focal male. Approaching stimulation manipulated the distance and so it must have affected the structural parameters of calls, which could be useful in the distance assessment. However, approaching stimulation did not affect the direction to the sound source. Therefore, if subjects respond with forward or backward movements (proxies of attack and retreat), it might suggest that they assessed the distance primarily based on structural parameters of calls or the change in the call amplitude. In contrast, if subjects respond with sideway movements, it might suggest that males required several independent measurements of different angles to the speaker to assess the distance reliably, and that the information from structural parameters of calls or the change in the call amplitude is insufficient.

\section{Materials and methods}

Study site and species

Experiments were conducted in the Upper Nurzec River Valley in Northeast Poland (centre of the study area: $23^{\circ} 14^{\prime}$ E and $52^{\circ} 36^{\prime} \mathrm{N}$ ) May 21 and June 6, 2012, between 2200 and 0215 hours local times. The test subjects were 70 territorial corncrake males randomly selected from larger populations.

Call stimuli, stimuli groups and experimental protocol

To prepare call stimuli, I used a total of $n=7020$-s-long samples of corncrake's natural broadcast calls recorded from different males in 2007-2008 in Kampinoski NP in Poland and digitised using the Avisoft SASLab Pro 4.52 sound analysis package ( $48 \mathrm{kHz} / 16$ bit PCM files). All calls were digitally prepared to match a $96 \pm 5-\mathrm{dB}$ signal pressure level (sound pressure level [SPL] at $1 \mathrm{~m}$ ) (natural level: mean: $96 \mathrm{~dB}$, range $80-101 \mathrm{~dB}$ ) and randomly assigned to two stimuli groups: with approaching and stationary stimuli. SPL(A) was measured with a CHY 650 (Ningbo, China) sound pressure level meter. For recording of samples, Sennheiser ME 62 microphones (frequency response: 150 $15,000 \mathrm{~Hz}, \pm 2 \mathrm{~dB}$ ) recording to an Edirol R-4 Pro Portable Recorder and Wave Editor (Hamamatsu, Japan) were used. Call samples used in both stimuli groups were recorded from similar distances (stationary stimuli: mean $\pm \mathrm{SE}=13.3 \pm 1.1 \mathrm{~m}$; approaching stimuli: mean $\pm \mathrm{SE}=14.4 \pm 0.9 \mathrm{~m} ; t$ test: $t=0.48$, $d f=68, P=0.634)$ and in similar field and weather conditions. Therefore, although experimental males listened to sounds affected to some degree by transmission through environment, sound transmission could not have differential effect on males' responses in both stimuli groups.

Before each trial, the loudspeaker was placed $<0.5 \mathrm{~m}$ above the ground, within the subject male's territory. During trials with approaching stimuli, the playback speaker was carried by the researcher toward the male. The approaching stimulation started immediately after the beginning of the 
playback and continued slowly directly toward the focal male until the end of the playback. The change of the distance was set not to exceed $4 \mathrm{~m}$. Such a change made a considerable though a small fraction of the initial distance of a male to the speaker (see "Results"), and it was chosen because of two reasons. Firstly, to minimise the deterrent effect of the intrusion itself. Because after the stimulation the speaker was still far away from a male, the movement itself could increase the concentration of a male rather that to threaten it. Secondly, to provide listeners with a considerable change in sound amplitude. During stationary trials, playback speaker was motionless throughout the trials; however, the person was standing close by. Because corncrakes call from within dense vegetation during the night, it was very unlikely for the males to see the researcher.

Data collection and analysis

For the playback experiments, I used a Creative ZEN player (quality of files: PCM, $48,000 \mathrm{~Hz}, 16$ bits) with a wireless SEKAKU WA-320 (Taichung, ROC Taiwan) loudspeaker with $20 \mathrm{~W}$ amplifier and $50-15,000 \mathrm{~Hz}$ frequency range. All of the experiments were conducted within an Acoustic Location System, which consisted of an array of four omnidirectional microphones (Sennheiser K6/ME 62) recording to an Edirol R-4 Pro 4-channel Portable Recorder and Wave Editor (Hamamatsu, Japan). I used the acoustic locator algorithm in XBAT (v. 0.6.1, Cornell Lab of Ornithology) to determine the position of focal subjects within the microphone array. Microphones were fixed at $1.5 \mathrm{~m}$ above the ground.

I measured the position of the focal male relative to the playback speaker continuously, having started right before the playback started and finished $10 \mathrm{~s}$ after the playback finished ( $30 \mathrm{~s}$ altogether). From this data set, I chose two positions defining the first movement of each male: the first one from before the playback started and the second one collected right after a male moved and stopped. Because corncrakes stop calling while moving, the choice of the second position was straightforward. Consequently, the change of the position between the first and second measurements was always the first movement, regardless of the number of movement recorded and the total distance covered by a male during the mentioned $30 \mathrm{~s}$.

Considering these positions, I calculated the angle of the first movement relative to the speaker $\left(0^{\circ}\right)$. Next, I categorised the angles into three classes: forward (between $315^{\circ}$ and $45^{\circ}$ ), backward (between $135^{\circ}$ and $225^{\circ}$ ) and sideways (between $45^{\circ}$ and $135^{\circ}$ or $225^{\circ}$ and $315^{\circ}$ ) movements. However, for simplicity, I transformed the angles $180^{\circ}-360^{\circ}$ into the corresponding $0^{\circ}-180^{\circ}$ angles.

For statistical analyses, I used both parametric ( $t$ test and $F$ test (ANOVA)) and nonparametric (Mann-Whitney test,
Kruskal-Wallis test and $\chi^{2}$ test with Yates correction for continuity) tests when data deviated from normality. I tested each variable for normality of distribution using the ShapiroWilk test. The variables distance of first reaction and initial distance of a male to the speaker were log-transformed. All $P$ values are two tailed.

\section{Results}

Although males from both stimuli groups had similar distances to the speaker before the experiment (stationary stimuli: mean \pm $\mathrm{SE}=33.96 \pm 2.24 \mathrm{~m}$; approaching stimuli: mean $\pm \mathrm{SE}=$ $31.78 \pm 2.64 \mathrm{~m} ; t=-1.24, d f=68, P=0.219)$, males subjected to approaching stimuli moved longer distances than males subjected to stationary stimuli (Fig. $1 ; t=2.36, d f=68$, $P=0.021$ ). Nevertheless, the angle between the initial position and the position after the first reaction was small in both groups (stationary stimuli: Q25/median $/ \mathrm{Q} 75=0.18 / 0.44 / 1.92^{\circ}$; approaching stimuli: Q25/median/Q75 $=0.19 / 0.64 / 2.23^{\circ}$; MannWhitney test: $\mathrm{U}=503.0, P=0.544)$. Consequently, a majority of males either moved toward or away from the playback speaker and only $11 \%$ of males in both stimuli groups moved sideways (Fig. 2). Assuming equal likelihood of moving sideways and forward or backward ( 0.5 vs. 0.5$)$, this difference was very unlikely to happen by chance $(<0.001)$.

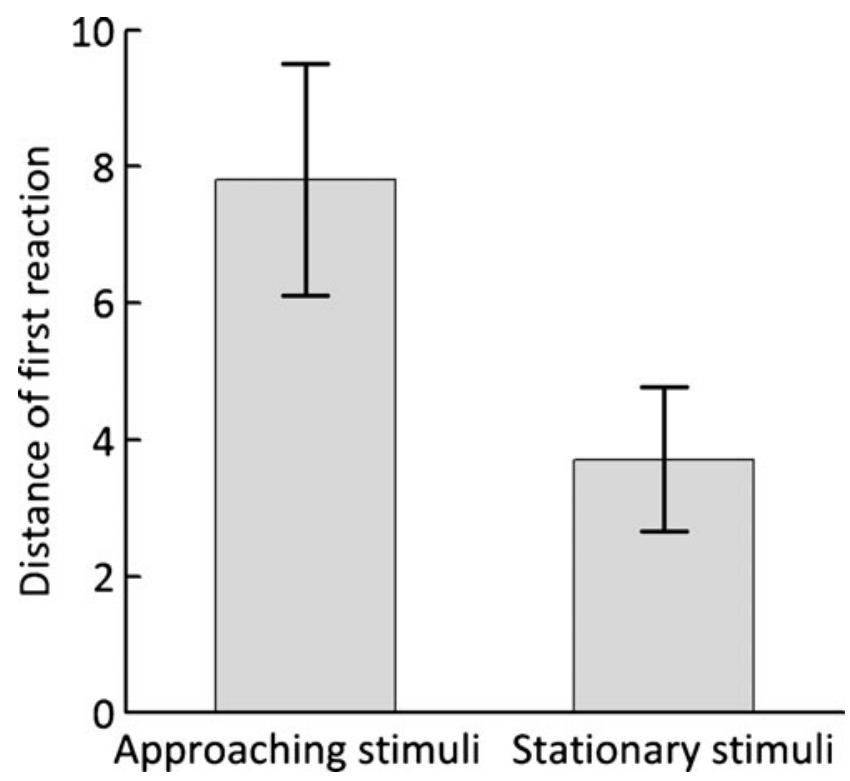

Fig. 1 Responses of focal males to two types of stimuli: with both acoustic and moving stimuli (approaching stimuli) and only with acoustic stimuli (stationary stimuli). The boxes show mean $( \pm \mathrm{SE})$ distances. In this graph, movements were included independent of their direction. Distance of first reaction was calculated measuring the distance between the position from before the playback started and the position measured right after a male moved for the first time and stopped (see "Materials and methods" for more details) 
Fig. 2 Distribution of the direction of first movements among males stimulated with approaching and stationary stimuli. Digits above bars indicate numbers of males

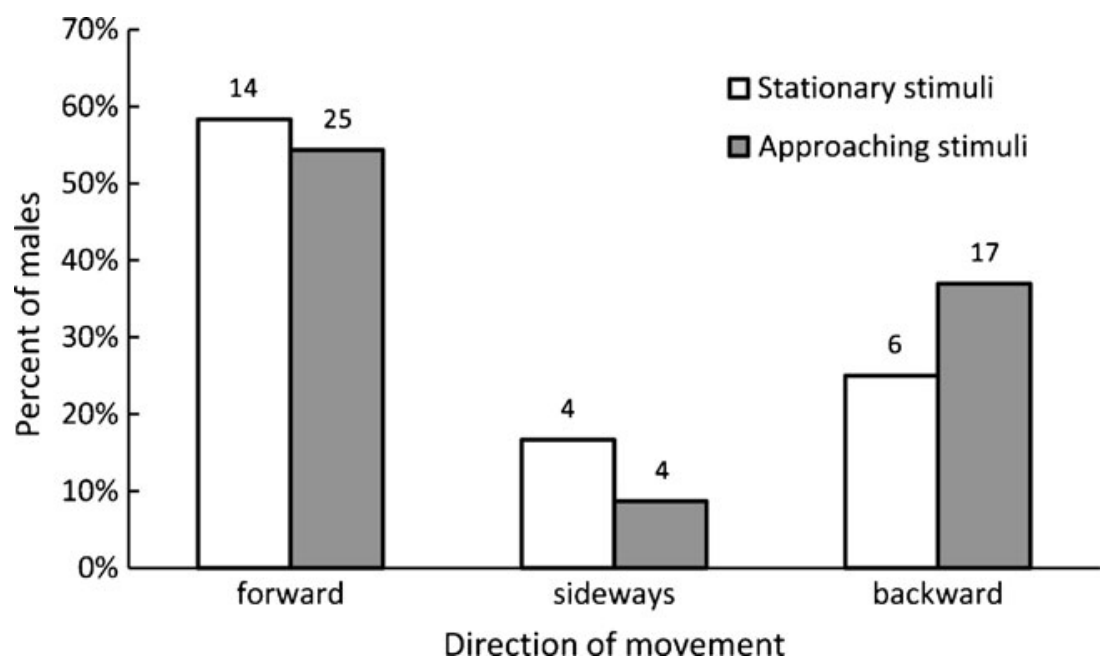

Males categorised as responding with forward, backward and sideway movements had similar initial distances to the speaker (forward: mean $\pm \mathrm{SE}=32.99 \pm 2.56 \mathrm{~m}$, backward: mean $\pm \mathrm{SE}=$ $31.41 \pm 3.34 \mathrm{~m}$, sideways: mean $\pm \mathrm{SE}=33.45 \pm 5.56 \mathrm{~m}$; Kruskal-Wallis test: $H=1.29, P=0.526$ ), and the difference between the numbers of males with forward or backward and sideway responses in both stimuli groups was not significant (Fig. $2 ; \chi^{2}=0.36, d f=1, P=0.549$ ). Therefore, the significantly lower number of males moving sideways neither could result from initial conditions nor from the effect of the stimuli themselves.

\section{Discussion}

Relatively small number of males making sideway movements compared with predominating forward and backward movements suggests that corncrakes did not move specifically in order to locate the source of the sound but that they moved toward or away from the already located sound. Because such an effect was independent of the stimulus, it might be concluded that corncrakes were not able to estimate or did not pay attention to the distance to the speaker. Nevertheless, the fact that males moved longer distances in response to approaching than stationary stimuli indicates they were able to perceive the change of the distance to the playback speaker based only on structural parameters or the amplitude of the calls played. This proves that males did pay attention to the distance per se. At the same time, the results gave no evidence for the active localisation. To justify these conclusions, they should be referred to both the general mechanisms of spatial imagination in birds as well as the specificity of the mating system of the corncrake.

Many types of birds' vocalisations appear to have acoustic structures adjusted specifically to the positioning of the sender (McGregor and Falls 1984; McGregor and Krebs
1984; Holland et al. 1998, 2001). Such a function is relatively well fulfilled by, so-called, broadcast signals, i.e. all kinds of territorial songs or calls directed to both males and females. Various parameters of broadcast signals change predictably during transmission through environment, providing receivers with better or worse estimates of the distance to the sender. Vocalisations characterised by wide frequency spectra and strong modulation of amplitude or frequency provide receivers with the best distance assessment cues (Naguib and Wiley 2001). Because higher frequencies are attenuated faster than lower ones, vocalisations received after longer transmission have narrower and lower frequency spectra than those received after shorter transmission. Similarly, modulated signals are prone to smear and extend with distance, which modify their structure: creates energy tails, fill in pauses and selectively attenuates or amplifies some frequencies (Slabbekoorn 2004). All these changes can provide listeners with relatively accurate information about the distance to the sender. At the other extreme, there are alarm calls with acoustic structures making them hard to locate (Klump et al. 1986; McGregor and Dabelsteen 1996). Such vocalisations, as might be predicted, have narrow frequency spectra and lack modulation (Kumar 2004; Marler 2004). Territorial call of the corncrake looks like a textbook example of the sound from the first group: it has wide-frequency spectrum and pulsating amplitude-modulated structure (Ręk and Osiejuk 2011). Besides, it is produced in long series, which minimises the error of measurements. Consequently, it appears that the structure of corncrake's broadcast calls provides listeners with a satisfactory set of distance assessment cues, without the need to fall back on the more timeconsuming techniques of active localisation.

The acoustic communication of the corncrake takes place in complex communication networks, consisting of several to even 20 simultaneously singing males. As in all territorial animals, it is crucial for corncrake males to keep at bay, and 
the distances among males are seldom smaller than $100 \mathrm{~m}$. Therefore, the precision of localisation seems not to be of the highest importance. Nevertheless, in conditions of extremely low visibility, vocalisations of the corncrake must play an especially important social role, limiting the frequency of territorial conflicts and facilitating mutual localisation. A male surrounded by a group of singing and known rivals should have satisfactory spatial information to orientate himself relative to other males and to detect potential reshuffles. It cannot be excluded, however, that corncrakes facilitate this process using calls of neighbours with known location as the acoustic background with points of reference for measuring changes in the distances. Such a process would be based on the assessment of quantitative relationships between the same acoustic parameters coming from different sources. Nevertheless, except for the studies on owls that evolved some anatomic adaptations (Moiseff 1989), we still know very little about mechanisms of sound location in nocturnal birds.

Acknowledgments I would like to thank Lucyna Wojas for her help during fieldwork and Tomasz Osiejuk for his comments on the manuscript. The work was supported by the National Science Centre (grant no. UMO-2011/03/D/NZ8/02133).

Open Access This article is distributed under the terms of the Creative Commons Attribution License which permits any use, distribution, and reproduction in any medium, provided the original author(s) and the source are credited.

\section{References}

Alonso JC, Magaña M, Álvarez-Martínez JM (2012) Male display areas in exploded leks: the importance of food resources for male mating success. Behav Ecol 23:1296-1307

Brumm H, Naguib M (2009) Environmental acoustics and the evolution of bird song. Adv Stud Behav 40:1-33

Brumm H, Ritschard M (2011) Song amplitude affects territorial aggression of male receivers in chaffinches. Behav Ecol 22:310-316

Brumm H, Zollinger SA (2011) The evolution of the Lombard effect: 100 years of psychoacoustic research. Behaviour 148:1173-1198

Coles RB, Guppy A (1988) Directional hearing in the barn owl (Tyto alba). J Comp Physiol A 163:117-133

Holland J, Dabelsteen T, Pedersen SB (1998) Degradation of wren Troglodytes troglodytes song: implications for information transfer and ranging. J Acoust Soc Am 103:2154-2166
Holland J, Dabelsteen T, Pedersen SB (2001) The location of ranging cues in wren song: evidence from calibrated interactive playback experiments. Behaviour 138:189-206

Ioalè P, Nozzolini M, Papi F (1990) Homing pigeons do extract directional information from olfactory stimuli. Behav Ecol Sociobiol 26:301-305

Jordan Price J, Johnson KP, Clayton DH (2004) The evolution of echolocation in swiftlets. J Avian Biol 35:135-143

Klump GM, Kretzschmar E, Curio E (1986) The hearing of an avian predator and its avian prey. Behav Ecol Sociobiol 18:317-323

Knudsen E, Blasdel G, Konishi M (1979) Sound localization by the barn owl (Tyto alba) measured with the search coil technique. J Comp Physiol 133:1-11

Konishi M (2003) Coding of auditory space. Annu Rev Neurosci 26:31-55

Kumar A (2004) Acoustic communication in the red-vented Bulbul Pycnonotus cafer. An Acad Bras Cienc 76:350-358

Makita Y (1962) On the directional localisation of sound in the stereophonic sound field. EBU Review 73(Part A-Technical):15361539

Marler P (2004) Bird calls: a cornucopia for communication. In: Marler P, Slabbekoorn H (eds) Nature's Music The Science of Birdsong. Elsevier Academic Press, San Diego, London, pp 132-177

McGregor PK, Dabelsteen T (1996) Communication networks. In: Kroodsma DE, Miller EH (eds) Ecology and evolution of acoustic communication in birds Cornell University Press. Ithaca, New York, pp 409-425

McGregor PK, Falls JB (1984) The response of western meadowlarks (Sturnella neglecta) to the playback of degraded and undegraded songs. Can J Zool 62:2125-2128

McGregor PK, Krebs JR (1984) Sound degradation as distance cue in great tit (Parus major). Behav Ecol Sociobiol 16:49-56

Moiseff A (1989) Bi-coordinate sound localization by the barn owl. J Comp Physiol A 164:637-644

Naguib M (1995) Auditory distance assessment of singing conspecifies in Carolina wrens: the role of reverberation and frequencydependent attenuation. Anim Behav 50:1297-1307

Naguib M, Klump GM, Hillmann E, Grießmann B, Teige T (2000) Assessment of auditory distance in a territorial songbird: accurate feat or rule of thumb? Anim Behav 59:715-721

Naguib M, Wiley RH (2001) Estimating the distance to a source of sound: mechanisms and adaptations for long-range communication. Anim Behav 62:825-837

Ręk P, Osiejuk TS (2011) No male identity information loss during call propagation through dense vegetation: the case of the corncrake. Behav Process 86:323-328

Slabbekoorn H (2004) Singing in the wild: the ecology of birdsong. In: Marler P, Slabbekoorn H (eds) Nature's Music The Science of Birdsong. Elsevier Academic Press, San Diego, London, pp 178-205

Waas JR (1991) The risks and benefits of signalling aggressive motivation: a study of cave-dwelling little blue penguins. Behav Ecol Sociobiol 29:139-146

Walcott C (1996) Pigeon homing: observations, experiments and confusions. J Exp Biol 199:21-27

Witten IB, Knudsen PF, Knudsen EI (2010) A dominance hierarchy of auditory spatial cues in barn owls. PLoS One 5:e10396 